\title{
Mobile Devices to Enhance Teaching and Learning in the Classroom: Some More Second Thoughts, Using Activity Theory
}

\author{
Anietie G. Ukpabio \\ 1.Doctoral Researcher of PhD in E-Research and Technology Enhanced Learning Lancaster University, UK \\ 2.Business Analyst at IBM Client Innovation Centre, Leicester, UK
}

\begin{abstract}
The focus of this interdisciplinary research is to comprehend the impacts of computing lecturers' deployment of mobile devices in the classroom for teaching and learning. Along this line of thought, the use of activity theory was paramount towards understanding the activity system which three lecturers work within. Their stances were investigated with emphasis on their lengthy years of experiences relating to teaching and learning especially using technology in addition to additional constituents of the activity system of teaching computing to higher education students within a further education college.A qualitative approach was used and the results delineate the existential nature of different ambiguities that posits at the continuum of between and within various components of the activity system. These inconsistencies include the deficiency in reflecting, teamwork, peer communication, the pressure to reduce the existing gap between theory and practice, issues with classroom sizes and the habitus of the classrooms in relation to technology enhanced learning (TEL). Numerous recommendations are put forward to alter the current state of interplay in teaching computing to higher education learners in addition to strategic deployment of mobile devices in the classroom towards fostering the growth of a technology-enhanced classroom. Keywords: Computing lecturers, mobile devices, mobile learning, m-learning, technology-enhanced classroom, activity system, activity theory, higher education, further education
\end{abstract}

DOI: $10.7176 / \mathrm{JEP} / 10-9-15$

Publication date:March $31^{\text {st }} 2019$

\section{Introduction}

Even though numerous studies have sufficiently discussed the advantages of learning using mobile devices (also known as m-learning), teachers are still hesitant to deploy the concept of learning through mobile devices in their professional practice (Ferguson, 2012). Inadequate finance frequently makes the list of reasons why m-learning is not a feasible endeavour. The affordability of the required mobile devices can be exorbitant for the students and teachers coupled with issues related to the security and privacy of private and sensitive information in public settings (Afreen, 2014). A recent study by Crompton (2013) implies that over 60 percent of mobile applications transmit data that the users do not intend to share without seeking consent or permission. Teachers may perceive an obligation of transforming from the standpoint of their professional habituality to a new standpoint required to assimilate m-learning in their professional practice. However, because the change required for assimilation is inevitable, (Crompton, 2013) mentioned that some teachers highlighted time limitation as a key barrier.

A few years ago, Mehdipour and Zerehkafi (2013) discussed the impediments affecting the implementation of m-learning that involved inadequate resources, insufficiency of knowhow required to assimilate m-learning, the people or contextual issue and issues with maintaining mobile technological uniformity across the institution. While these issues may seem commonplace in the discourse beyond m-learning, it is worth mentioning that they remain prevalent in the concept of m-learning in higher education (Sharples, 2013). This study adopts a stance that seeks to understand how mobile devices are used in the classroom with cognisance of numerous practicalities discussed by Mehdipour and Zerehkafi (2013) and Sharples (2003).

A study by Buabeng-Andoh (2012) suggests that the most protruding problem in m-learning is the inadequacy of reviews about the use of mobile devices in higher education for teaching and learning as well as a standardised framework to efficiently study and determine the impact, underpinnings, and intricacies of m-learning (Fulantelli et al., 2015). Numerous efforts to theorise m-learning have been made (by Pachman, Logunov, \& Quinton 2011; Vavoula \& Sharples 2009; Traxler 2007), so far, they all lack the support and rigor required towards embracing generalisability and coping with the ever-changing technological communities and innovation. However, generalisability is not the intention of this study as it seeks to explore qualitatively and contextually, how computing teachers use mobile devices in their classrooms for teaching and learning, from an activity theory perspective.

\subsection{Study aim and questions}

To accentuate further about the introductory discussion above, this research focuses on understanding how mobile devices are used by learners through their lecturers. The objectives of the research are submerged in the main and sub-research questions which were to start with a broad question that inquires how lecturers of computing evaluate their attempts to integrate mobile devices into teaching in an HE-in-FE (Higher Education in Further Education) 
setting? Beyond this main question, it was vital to maximise the advantage of such a relatively comprehensive question by complementing it with a significant follow-up (sub) question which abetted the formation of themes and strengthened the narrative thread section of the literature review. The question is:

a. What are computing lecturers' motivation towards transforming an object into outcome?

b. How do computing lecturers use mobile devices alongside other artefacts in the classroom?

c. How do social structures impact the use of mobile devices in teaching computing in the classroom?

Correspondingly, in line with the suggestions of a few researchers (like, Patton, 2002; Cresswell, 2009), which underscored that study a method should be shaped by the research aims and questions, a qualitative method was implemented for this research. Principally, a technique of associating the study questions to the issues in the context and a further association with the past and evolving themes in existing literature was adopted.

\section{Review of relevant literature}

Teaching and learning from mobile devices challenges numerous underpinning conventions that have existed for a long time about teaching and learning in higher education. It challenges the intelligence, timing and fixed spaces of tested and trusted teaching methods and the importance of conventional resources and tools. Its affordances in relation to the suitability of its theoretical framework can empower lecturers to embrace mobile learning in viable and substantial ways and to guarantee that this notion keeps evolving with new ideas and technological advancements. However, its suitability is hugely debated to be more contextual and conceptual than its arguable generalizability. Progressively, research is expected to build up these affordances with regards to fitting more hypothetical underpinnings and academic applications (Wu et al., 2012). However, a review of some of the considerations of using mobile devices in the classroom within a higher education context, particularly in teaching computing, are discussed below.

\subsection{The technology, the reality, and the dimension}

The theoretical fundamentals of learning have shifted at a fast pace within the past few decades from a behaviouralist to cognitivist and later to constructivist perspective, and it is the intersection of the developments in theory and the affordances of technology that may make the turbulence that could be caused by these shifts easy for lecturers in higher education to cope with. Also, there is the conceptual move in philosophical, hypothetical and professional dimension about educational technology which has been strengthened by many researches about the use of technology in higher education and can be recognised over numerous dimensions.

The ease of availability, affordable cost, portability, and tractability has lured teachers to increase the use of mobile devices within and beyond the classroom (see Jacob and Issac, 2014a; Jacob and Issac, 2014b; Berson et al., 2012; Picek and Grcic, 2013). There are, however, concerns about whether mobile devices are sustainable in the higher education sector which is discussed in an intertwined manner in the subsequent sections of this study. Nevertheless, in addition to the probable capacity of mobile devices as an educational tool, concerns exist which are fuelled by challenges such as considerably slow data transmission, small-sized screen and keyboard and relatively limited functionality as compared with desktop computers. Other concerns include the negative effect that mobile technology might have to student's learning. Recently, some studies showed that learners who multitask with high involvement in social media platforms and instant messaging might struggle to complete their academic tasks or complete at a very low-quality standard (Spangler et al., 2016; Brown and Mbati, 2015; Kuznekoff et al., 2015; Wishart, 2016). While this is the case for medium-aged learners, younger learners who, frequently, use the same devices portray decreased persistence in engaged observation. Wilkinson and Barter (2016) stressed that the inconsistency and incompatibility between the disruptive nature of mobile devices and the current nature of learning contexts is one of the main challenges in designing mobile learning contexts. This study embraces these initial findings of Wilkinson and Barter (2016) by helping to comprehend how learners make use of mobile devices in the classroom and how this might yield information about how and when the mobile device can be used in the classroom.

In addition to the challenges pointed out above, the essentiality of mobile devices in encouraging selfregulated learning and supporting constructivist pedagogy cannot be misconstrued to be concurrent to the myriad benefits that can be gained from its use. Its use, however, requires the use of a framework that ensures its consistency and compatibility with the theoretical frameworks. From a holistic point of view, mobile devices have a great potential to support learner's cognitive ability through the identified characteristics. Its potential is, nonetheless, connected to its usage and the type of learning and activity it supports. However, these seemingly negative realities and dimensions is not the only focus of underpinning literature from which this research builds upon; other relevant literature are reviewed below.

\subsection{Digital exclusion or digital choice in mobile learning?}

Some higher education lecturers are not comfortable about their use of technology, feel fairly undermined for the fact that most of their learners are more technology capable and technology competent than them. Peters (2005) 
found that teachers who might be exceptionally happy with using desktop computers are not competently used to using mobile technologies - unlike their students. The possibility that there are generational contrasts in learning styles, for example between the "Baby Boomers," "GenXers," "Millennials," "Neomillennials," just to mention a few., has experienced much innovation money over the most recent couple of years. Additionally, according to Reeves (2007), a review of several exploratory studies on generational learning styles yielded insights that the larger part of these review studies is methodologically defective, and that contrasts in generational differences of computer development are more notable than contrasts between the learning styles.

Whilst it is not the objective of this research to argue that a specific learning style for teaching computing to students may require the utilisation of specific technology, it is worth mentioning that some students are more abreast with technological advances, and that it may have an essential influence in normal non-academic activities, therefore making the use of gadgets unavoidable, especially for young students. The system in which these portable and unavoidable technologies are utilised suggests that they have much potentials to be utilised as one of the core tools teaching and learning in higher education. Nonetheless, for some teachers, it is easier to disallow the utilisation of these "turbulent" advancements than to risk it being used because they cannot fully comprehend or recognise how they are being used or how they can be used (Reeves, 2007).

The negative effect of this is that the teachers may turn out to be progressively conceptually distanced from a most of their students because of the gap in technological communication. The instructive and sociological impacts of these technologies are huge for teachers, not just for the need to comprehend the way students communicate, but to understand the pace at which the interaction between system environments evolves (Desai et al., 2008).

\subsection{The emergent mobile technological trends}

Broadly stating, mobile learning (also known as m-learning), in a simplified definition can be regarded as learning activities undertaken through the use of mobile devices (Thüs et al., 2012) and a type of learning that has developed the authenticity of "nomadic" learners - learners that are constantly on the move and or changing locations (Gorodetsky and Barak, 2016). While it has been portrayed as an evolving pattern of innovatory advancement, some higher education institutions have embraced m-learning concepts and technologies, and in those that have, it is uncertain that they are being utilised in an educationally suitable manner. For example, some teachers in the higher education institutions in the United Kingdom (UK) have made use of short messaging service (SMS) as reminders for ongoing course prerequisites, quizzes, voting with a few American universities exploring different avenues regarding mobile phone examinations that uses voice recognition mechanism to authenticate the students as the rightful examination candidate (RadOnc eLearning Center, 2017). According to Desai et al. (2008), there is evidence that some young students despise the use of their favourite mobile devices for learning activities that give more control to the teacher than the student (i.e. a teacher-centred activity). Brown and Mbati (2015) studied the manner in which some educational institutions use handheld devices that are very personal to the students (such as PDA - personal digital assistants), and realised that educational data processing such as storage and retrieval of electronic books, other courseware, and timetables are the general practices of mobile devices in the classroom. Additionally, advanced sound players, for example, Apple's products like the iPod have basically been used higher education to "convene" lectures that are recorded and consequently made available on the internet through a technique known as really simple syndicate (RSS) channels or feeds to the students' for streaming or download (Kuznekoff et al., 2015). These devices enable the students to listen to the messages anywhere, anytime, without restrictions.

A system for categorising the academic importance of mobile technologies proposed by Rossing et al. (2012) implies that the practices discussed so far are mostly related to administrative tasks like timetables, electronic books, quizzes, and voting, etc. They argue that the hypothetical underpinnings of these exercises seem, by all accounts, to be either non-existent or mainly behaviourist in nature. More importantly, to wager or disregard this proposition, it is worth considering a few more possible scenarios for the use of mobile devices in the classroom below. 


\section{Theoretical Framework}

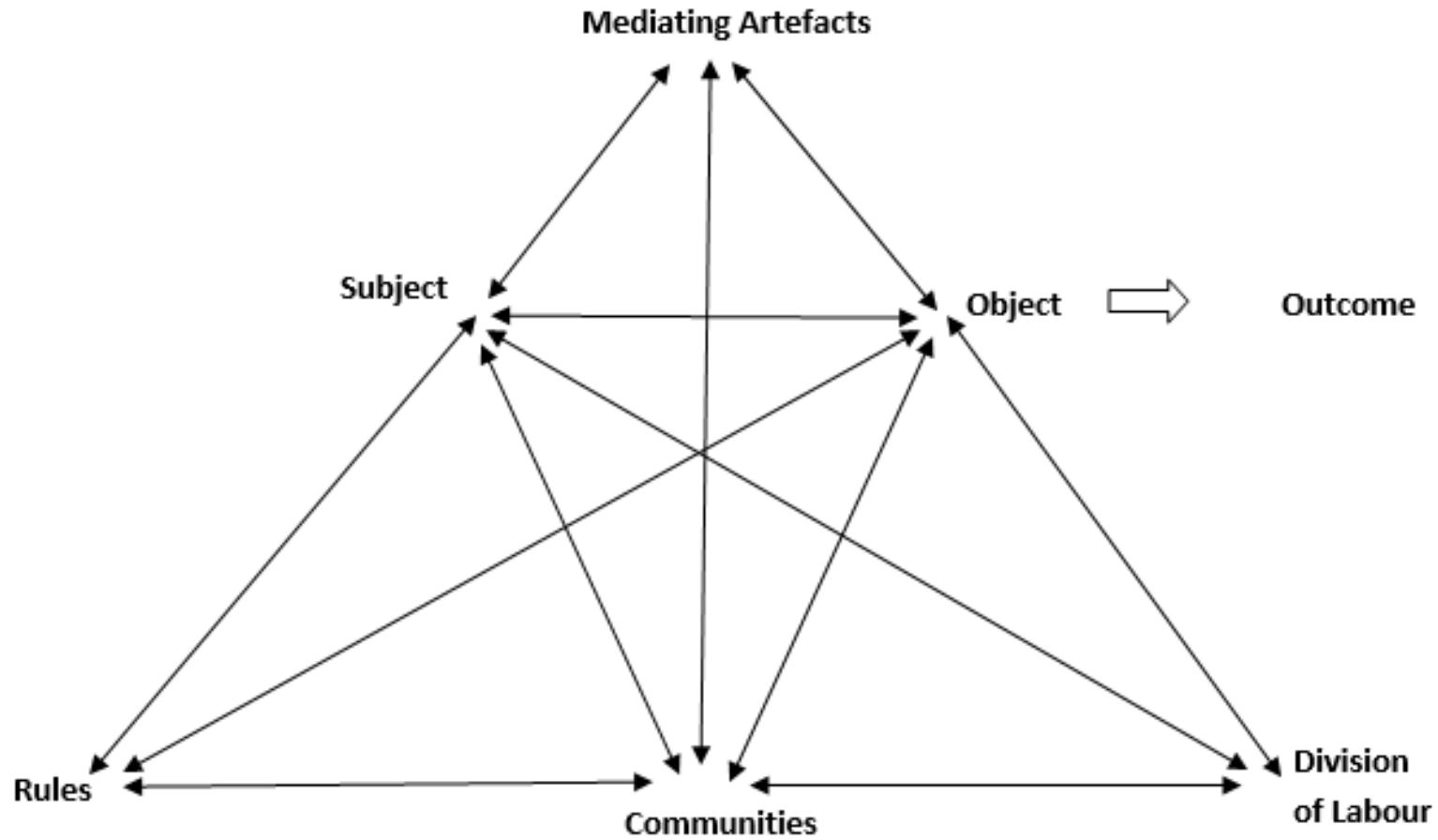

3.1 The habitus of cultural-historical activity theory

As activity theory is an embodiment of a structured inquiry within a framework of elements (extensively consisted of subject, object, outcome, artefacts, community, division of labour and rules) within an activity system. The elements are culturally facilitated human activity or activity system (Engeström and Miettinen, 1999). Although, through differentiating the historical, societal and disjointed yet connectively shared nature of activities, Engeström proposed the collective activity system (see Figure 1).

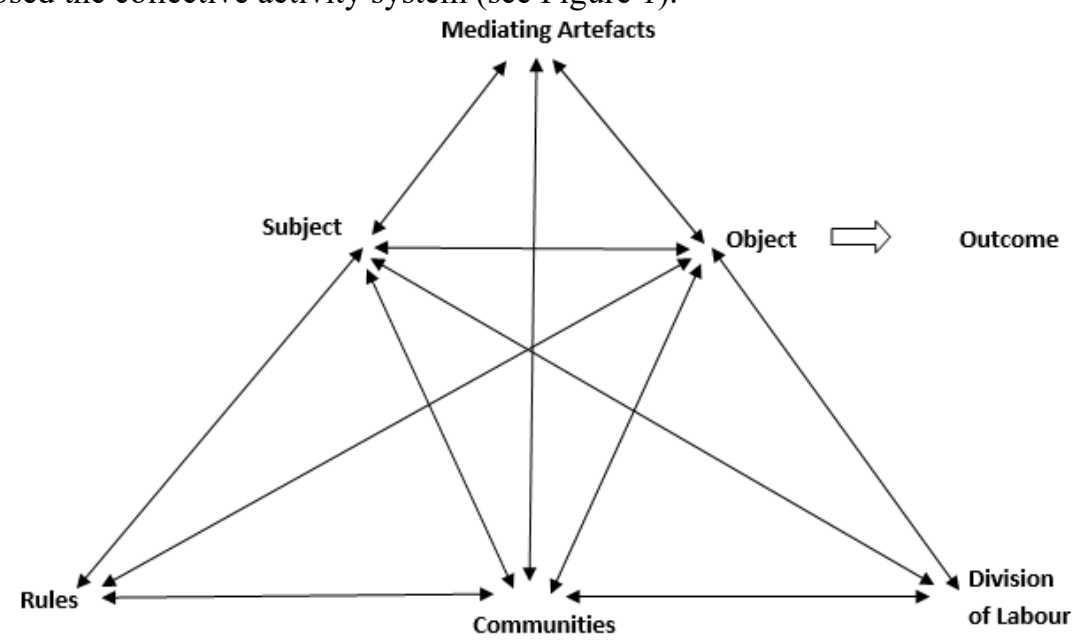

Figure 1. Engeström's Activity Theory Model

To exemplify further, in the diagram above, it is a reasonable assumption to consider teaching and learning of computing as the object. Researchers, lecturers, and other college administrative personnel are an embodiment of the system via intricate connections. For this system, there is an involvement of numerous communities whose interactions with each other is facilitated by the background object.

Given that activity systems are differentiated by their objects, in this instance, there are different groups of people collaborating with each other amid the background object. The transformation of an object into an outcome is an underlying need of the subjects (computing lecturers), which "comprises of societally essential new, objectrelated implications and fairly permanent new forms of interactions" (Engeström, 1999,). Within an activity system of teaching computing, the result may oscillate between the establishment of new learning communities and the creation and utilisation of new knowledgeable tools, as opposed to the theoretical underpinnings of teaching computing. 
Conversely, the transformation is geared towards achieving a result from the object; it is the process during which the object drives profitably to result. At the end of the process, there is a conceptual divide between the object and the result that should be bridged by transforming the framework. Division of labour is one of the main coordination characteristics of a community in transforming an object into the result.

Along this concept, this comprises both the horizontal division of tasks between the individuals from the group and to the vertical division of power and status. The rules comprise of the controls, standards, and traditions that concentrate and compel activities and associations within the activity system.

Also, it is a reasonable assumption that when a change is invoked by the subjects towards modifying the components of an activity system, internal ambiguities or contradictions, or, alternatively a range of conflicts, either inside or between various components of an activity framework, may be invoked. Although it may sound negative and insufficient, inconsistencies and the determination to resolve them are some of the main motivation of progress and improvement within an activity system. Activity systems are quite often in fluidity as the framework works through inconsistencies.

The focus of this research is to understand the ways in which mobile devices are utilised in effective teaching and learning of higher education computing course. How the subjects (lecturers and learners) teach and learn computing within the specified objective environment. The subjects of the activity system for the analysis of this study are three computing lecturers who teach (or are supposed to teach) within a technology enhanced classroom in the South East of England. The object here refers to the textbooks, supplies, computers and related electronic equipment and physical environment beyond the classroom, mediating artefacts, teaching methods as well as learning technologies. The figure below shows the activity framework employed in the analysis of teaching and learning of computing using mobile devices.

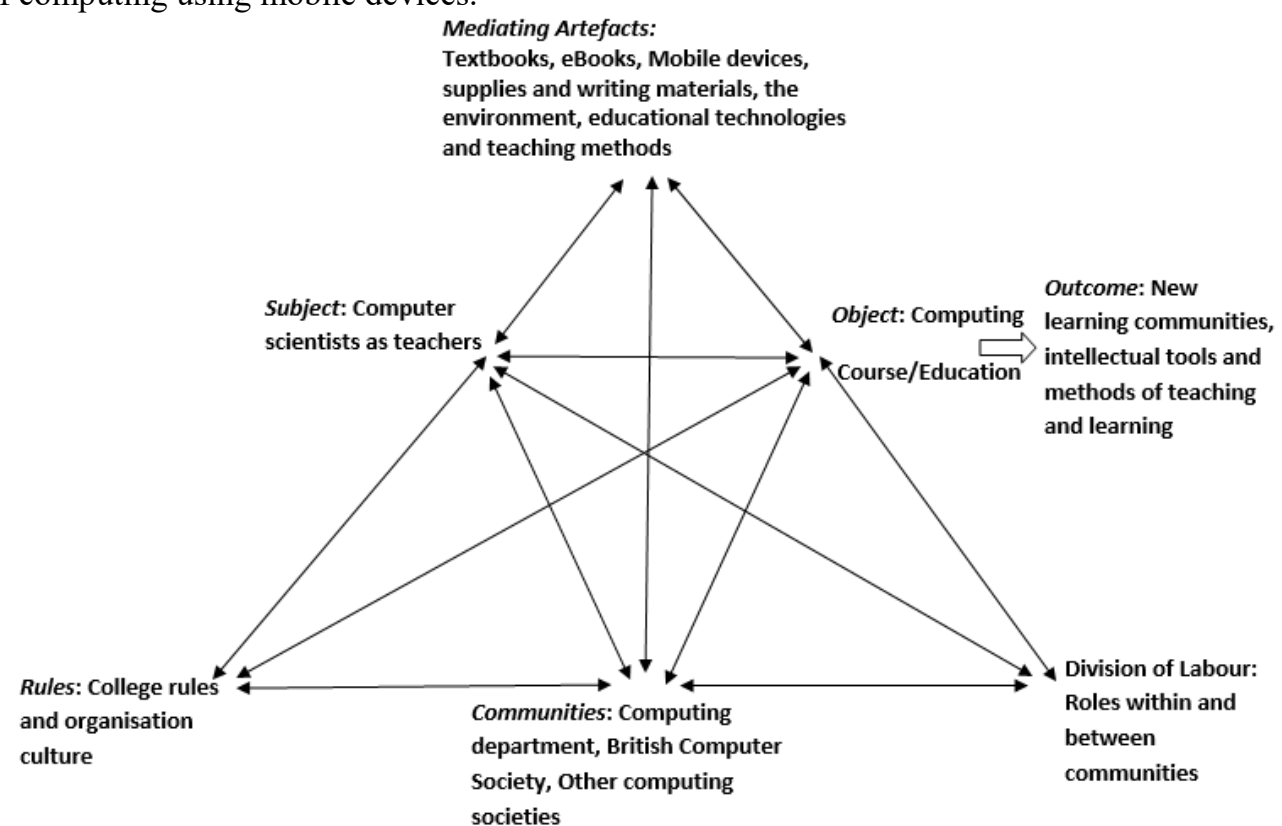

Figure 2. The Computing Department Activity System (Based on Engeström's Activity Theory Model)

The various communities that have a similar object in this study comprise of the entire college, particularly the computing department and its members, the top layer management, ideally, these subjects and the groups work in harmony towards teaching computing. All communities in each of the groups play a significant role within the activity framework (a division of labour) and, in general, they have an "amassed obligation" (Kaptelinin and Nardi, 2012) towards achieving the objective. The mediating artefacts adopted by the subjects are those that were developed in the structure of the institution and the culture of the system. A primary concern, therefore, focuses on exploring the three computing lecturers' deployment of mobile technologies in their classroom, couple with an understanding of their convictions about using these technologies in their teaching. Consequently, one imperative part of the study using this framework is understanding the subjects, their beliefs about teaching and learning, and their experiences and perceptions of teaching and learning using mobile devices. This study is further supported by portraying different segments of the activity system by analysing the conceivable forces, inconsistencies and discrepancies existing within or between system's components that might impede teaching and learning computing as well as its impact on introducing new technological ways of teaching and learning.

\section{Methodology and Method}

Methodologically, very frequently in educational research, a distinction is made between methodology and 
methods only to be disregarded at a practical or theoretical level. This practical and theoretical neglecting sometimes attempt to make researchers ignore that methodology connotes the justifications of approaches used to conduct research while method connotes the approaches adopted towards conducting research. This study draws from this complementary relationship that exists between a methodology and method.

A deductive standpoint was adopted by forming research questions that would help achieve the aims of the study while testing an existing theory (activity theory) that is a core theoretical framework of this study. A stance was adopted towards understanding how reality is shaped by the social, political, cultural, economic, and ethnic and gender values towards becoming socially co-constructed (Cresswell, 2009). A more detailed account of the events that transpired during the deployment of the method is discussed in an intertwined manner in the subsections (see section 4.1 and 4.2) of this chapter.

\subsection{Context of the study}

The research settings and location were in a further education college that runs higher education courses in collaboration with its partner universities. The College is in the south east of England and has no academic degrees awarding powers other than its diplomas. The context includes the subjects, communities, rules and their interactions within one and other components in the activity system. As expressed in the college's quarterly publication, the college rationality of higher education extends beyond the traditional 'acquisition of skills' needed for employment but also focuses on students learning both art and science in other to adjust to the current changes in the world and to be globally competitive.

\subsection{Method (Study design)}

This research focuses on the teaching of undergraduate computing by three computing lecturers, anonymously referred to as Sam, Bob, and Sarah, as an exploration was carried out to comprehend the way they are influenced by their use of mobile devices in teaching. The members and the settings in which they work will be portrayed in more detail in the discussion of findings section (Reeves, 2006). The interview structure was semi-structured format (Cresswell, 2009) which was thematically structured in a sequential manner with some suggested questions, and also willingness to modify the questions according to the responses received from the interviewees during the interview. The interviews were recorded, perused multiple times while transcribing it.

A brief description of the research was provided before the lecturers' interview which reassured the participants that absolute anonymity would be adhered to as well as the exact location of the study. Several interviews were conducted with each of the teachers, a few of them were physical interviews, and the majority were via conducted virtually. The initial physical interviews ranged between 40 to 60 minutes in length as the emphasis was to understand the teachers' beliefs of teaching computing, their meaning of m-learning and teaching technology with technology. The course handouts, syllabi, past examination papers, assignments, quizzes, the lecturers' virtual learning environment space (on Moodle), Sam's "short debrief" electronically conveyed sometimes to the students for their assessments about different aspects of the course, and the sites created by Sam's students as tasks for additional credit were utilised. The purpose was to develop an understanding of the teaching and learning of the participants and their way of dealing with the use of mobile devices in their classrooms. Different sources were examined, for example, college and departmental quarterly publication entitled "We Teach, We Learn", to better comprehend the settings of the research. These materials supplemented the understanding and perception on the interview conducted. The qualitative data was analysed with activity theory in focus as a theoretical lens.

The data analysis was in three stages. The first stage was analysing the material, at this stage, potential questions for the interview was determined. The second stage was interpreting the audio recordings and coding the interpretations, while carrying out member checking procedure to confirm the constructions of meaning with the interviewees, and to avoid inappropriate and unintended understandings of the interview data (Cresswell, 2009). The third stage was categorising the emerging patterns of these three subjects; Belief of computing teaching, perception towards mobile devices and learning experiences in diagram trees. Translations and interpretation of the similarities and contrasts considering the three subjects and their interrelations were made.

\section{Discussion}

\subsection{How the lecturers perceive teaching}

Among the participants, Bob was older than Sam, and he is nearing the end of his teaching career. He stated that he uses Textbooks, e-books, PowerPoint slides and interactions in addressing students. According to him, the students in his classes are respectful, tuning into his teachings quietly and precisely. Almost the greater part of the students is said to be occupied with notes taking using various mobile devices, or trying to type various snippets of computer codes that Bob displays on the board. Those not effectively taking notes sat, listened and viewed the whiteboard. However, Sarah's account contradicted Bob's account.

A common practice in Bob's lecturing was for the students to study the course textbook and solve 
programmatical problems that are geared to the ones that should be expected in examinations and coursework. He connected the issues that he tackled in class to the issues on the mid-semester or final examinations. Bob ascribed "great" teaching to the teacher's identity. He remarked,

"I think lecturing is an appearance of one's identity whether you are excellent at it or not" (interview, 29

March 2017).

He firmly alleged that "great" teaching was unequivocally subjected to how well the teacher clarifies things and how well he conveys new information. He perceived that his methods for addressing students, which he characterized as standing up before the students and clarifying things in own words are the best way of making students understand the subject than using technology to enhance his teachings. Based on Bob's account, his energy to address was apparent, as well, as he often walked around the class and strolled among the students' desks while talking calmly, offering explanations at a quick clasp. While this account differs from Sarah, who prefers to use well-designed slides as well as strategic use of words to deliver her lectures.

His approach to teaching highlights the collaborations between the subject and the object in the activity theory of teaching computing compelling the associations within and among other components. In his pattern of teaching computing, Bob believes that teachers are the most important component in the activity system and gives little or no regards to the other components. His proximity to students is used to the positive advantage of making sure the students understood the lesson. His eloquent speeches, intolerance for educational technology and fast pace teaching stems from an overloaded curriculum versus a limited time of course completion; this shows an inconsistency between the subject and the college's standards in the activity system towards the act of teaching computing with understanding. Bob also believed that teaching a large number of students reduces his interaction and flow of information since not all will be able to participate in class in the short questions he frequently asks during lectures.

Technology can help only to one point, yes [can enhance teaching and learning]. Considering that.. the technology will let you to get a display with more clarity, which can be a useful tool...the place in which the lecture should be improved, which will improve learning, up to the level where computers will help in learning, that will be an improvement, such a thing, such technology... But I trust that technology would never be superior to a person who has gained knowledge throughout the ages and knows how to communicate to pass it along to others. I always note down each small detail on a projected paper so that I will be able to express them on the go, this lets me show my work to anyone who has a question. (Interview, 29 March, 2017).

In summary, in Bob's approach to teaching, the flow of information is from the teacher to the students and technology is disruptive as opposed to an enhancement, a point of view that does not resonate with Sarah's point of view.

I am a firm believer of lecturing to students, also having personal interactions with each one of them personally.. I also want to maintain interactions within the classroom.. I am also of the opinion that teaching should occur not only from the text as well as the lecturer, to perfectly place them together and also to align them in perfect perspective ... (Interview, 29 March, 2017).

On the other hand, Sam believes in collaboration and innovation. Sam was ten years younger than Bob and ten years older than Sarah and had an extremely charismatic identity, his account appeared to include the other parts in the activity system and, highlighting the connections among them. For instance, Sam depended on other mediating artefacts other than the traditional textbooks and lecturing, and furthermore, he was in constant contact with the British Computing Society (BCS) to enhance his teaching.

Sam's method of teaching was unpredictable and diverse and consisted of the use of various tools and techniques both technological and beyond. Sam tracked his students' learning progress and made changes to the modules to make the students actively involved and interested in computing. For example, he gives his students the opportunity to research and explain their understanding of the issues under discussion making them more active in class participation. According to him, the students had a tendency to ask him more questions after these critical thinking sessions. This activity resonated with the students preferred method of learning, making them more dynamic learners.

Furthermore, his belief about teaching conforms to his use of technology especially mobile devices in teaching students, by creating activities for facilitating student learning.

I urge the students under me to carefully read the textbook as it a source of knowledge, after which... I attempt to provide my idea regarding that particular content and general idea of chemistry... As you know, just the way how things are related to each other and that proves there is chemistry. I also ask them to do questions because that will makes them learn better...I have no believe that one thing works for all the students. That is exactly why you need different ways of getting through to your students... (Interview, 29 March, 2017).

5.2 Technology in the classroom or disruption in the classroom?

Bob believes in the traditional method of teaching by explaining to students using his own knowledge, textbooks 
and other traditional resources, therefore, the other mediating artefacts contributions are minimal. He believes that mobile devices can hinder students understanding of the real basic issues and it can reduce the effectiveness of his teaching. The technology he employed like the projected screen is mainly a visual aid and to simplify complex discussions during lectures. He believed that negative impact of mobile devices on students learning is higher than the benefits and that it gives the illusion to the students hindering them from seeing the reality.

I simply cannot do that with all of my students [possibility of one on one interaction].I would give answers to a number of questions. The class the that I have now is an hour long with over 130 students, so during that would answer about maybe 6-8 quickly and with short answers, the more questions than that come from help sessions, from recitations and things of this sort... (Interview, 29 March, 2017).

The argument of Bob about mobile devices is partially embraced by Sarah who also contradicted the assumptions that mobiles devices will be openly embraced as a tool for teaching because like Bob, there is more emphasis on the role of communication and good explanation than of aiding them with mobile devices.

I do provide them some time to solve the classroom problems using their mobile devices. When they can talk to their partner, as an example I will do a question, after that I will hand them a very similar one which they are asked to do in the class rather than taking it home. .. Which will make them think more and generally after which several questions which would pop up additionally if no such thing was done in the same time duration ... (Interview, 29 March, 2017).

Sam, unlike Bob, he understood the impact of mobile devices and its application in enhancing knowledge and to improve student's participation in class and to assist them to survive in the present digital age. He uses the VLE website or mobile application (called Moodle) to communicate with students, uploading educational materials, syllabus, links to contemporary information as well as a detailed demonstration of computer programming practical sessions. He also uses the medium to remind students of dates, time and lecture venues as well as submissions of assignments, class discussions and group projects. He encouraged students on communication through sending of emails and group chats. His PowerPoint slides for the electronic board also include recent technologies in relation to computing to keep his students upgraded, and the board can be connected to the students' devices which enable them to ask questions anonymously and easily. Also, he encouraged students to interact and discuss using mobile devices. It is safe to say that Sam is a supporter of the Bring your own device (BYOD) or Bring your own technology (BYOT) concepts (see Afreen, 2014).

I had the need [aim of them using technology] for them to get accustomed to technology, making them know of the vast knowledge which is present getting them aware on the need of their own one [web page].I have students who said, "I can't believe it, I knew...I always knew I can do it, But never knew how to!" which provides them with an opportunity (Interview, 29 March, 2017).

In the use of emails, Bob employed it for communicating with students, to answer their questions related to the lessons, Sarah stated that she used it to constantly remind the students to get things done, while Sam used it as a means of getting to know his students better in addition to using it as a medium to answering their questions.

The three lecturers believed that the classroom setting was not ideal for effectively teaching computing, because, teaching large class seems to be a disadvantage to effective learning, especially for the students at the back row who can only view and listen to the lectures in the class via the projected screen, therefore, interacting with each of the students is practically impossible. For Bob, the technological structure of the lecture venue does not conform to his belief in explanation and does not allow for full communication with each of the students to benefit maximally from the course regardless of if it is a mobile device or not. For Sam, he tried to employ different strategies of imbibing mobile devices in teaching, but despite this, the class structure fails to support his view and belief fully because of some factors that were beyond his control. For Sarah, she tries to use various tools including mobile devices but only embraces them with skepticism as the extreme can be detrimental to teaching and learning in the classroom. These factors will be discussed in an intertwined manner in the discussion, contradictions and conclusion section.

\subsection{Study findings}

Contradictorily, this framework shows that there exist some contradictions in the system. As the non-perforated arrows represent the interaction between components while the perforated arrows show the contradictions in the system. 


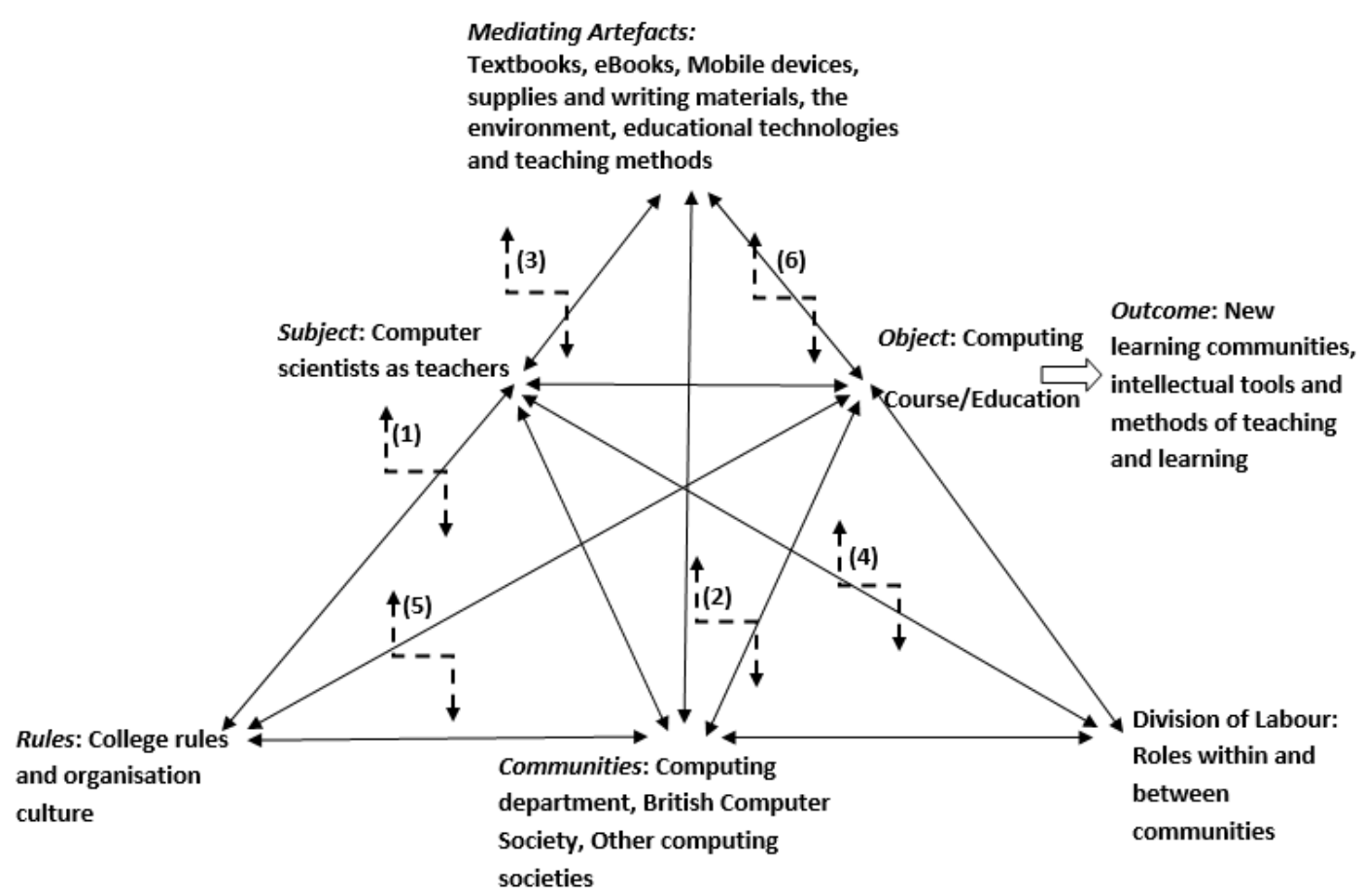

Figure 3. The contradictions in the teaching computing activity system (plain arrows connotes the interactions

between the components of the activity system while perforated arrows connote the contradictions).

The first contradiction labelled as "(1)" exists among the subjects, that is, the computing lecturers. It shows the perception of lecturers towards using mobile devices and other technology to teach, some use it fully, and others do not fully support its use. The second contradiction labelled as "(2)" represents the teaching culture. Some lecturers prefer the traditional teacher-centred teaching style while others like Sam are shifting towards the studentbased approach. The third contradiction labelled as "(3)" shows relationship constraints between the subjects and the mediating artefacts, this demonstrates the presence of tension due to insufficient collaboration and communication on issues related to teaching and learning. The fourth contradiction labelled as "(4)" reflects that issues related to teaching and learning were not focused on in the computing department and a possibility of an absolute negligence about such issues across the institution. The fifth contradiction labelled as "(5)" reflects that issues like large class sizes have no benefit than it reduces the college's expenses and maximizes their profit at the detriment of teaching and learning. Also, the classrooms were not technologically designed for proper learning. The sixth contradiction labelled as "(6)" reflects how inadequate rooms (mediating artefacts) deign of technology aided lecture can obstruct teaching and learning (objects) regardless of the pedagogy deployed.

Also, at the beginning of the data analysis, Bob's remarks, beliefs, and approaches to teaching, were in sharp dichotomy to Sam's. Sam's perspectives on the role of technology in teaching computing were more transformative and sophisticated and contrasted Bob's. Accordingly, Bob's case disconfirmed the basic assumptions that support the use mobile devices in teaching. His "negative case" constrained towards making new associations among the segments of the activity system (Kaptelinin and Nardi, 2006) and to search for illustrative inconsistencies. This does not negate the fact that Sarah's views came across as balanced. She gave a median remark that was merely interpretive (she was an "in-betweener" - was not at either extreme of the spectrum). So, at the fifth phase, with the theoretical lens of activity theory, a search was made for conceivable disagreements among the components of the computing teaching system. A triangulation of several data sources was carried out, for example, the perceptions, interviews, and materials making sure that the teaching computing using mobile devices was researched, from various viewpoints, utilising different approaches to illuminate meaning (Creswell, 2009).

It would appear that in Bob's case, the teacher is the main component of the framework, and the other components play minor roles, and their influence on his teachings was very weak. The subject believes in his role in explaining the issues to students as well as communications; this means that, if a teacher knows his responsibilities, teaching students will be easier and they can understand the topic under consideration better without enhancing it with mobile devices or technology. It is based on the traditional method of teaching, based on solving problems and the use of traditional materials like textbooks and assignments, while Sam strongly believed in using mobile devices and other technologies as a major tool for teaching and learning, he believed that this method would help the students to be independent and responsible, it will also help them to keep abreast with the current issues and trends in computing, this is evident on his using of VLE website (Moodle) in communicating with students as well as being a member of the British Computer Society (BCS). By mobile devices, his belief has 
shifted from the traditional method of teacher-centred towards student-centred teaching approach by embracing. Sarah's beliefs tended to resonate with both sides but resonated more with Bob's beliefs.

\section{Conclusion}

The three cases presented in this study assisted towards understanding the teaching of computing and the role of mobile devices in the classroom in the teaching process. As seen from the study, the emphasis on technology in the institution is based on the college's philosophy and its links to its cultural schemas and resources. According to Aikenhead and Jegede (1999), resources are effects of schemas and schemas are effects of resource, the agents within the institution are reinforced by the college's structure for the purpose of transformation, and this study reflects that agents do not use resources, the primary resource in this study is Technology. Which characterises this discrepancy to the different culture and beliefs of the subjects in the three cases, for example, according to Sarah, Sam and Bob's narrative accounts, it would appear that Bob used technology as a limited tool to support his teaching method, Sam used it effectively as a means of communicating with students as well as for effective teaching and learning method and Sarah used it for constantly reminding students about what is expected from them.

The three themes of the subjects are their teaching belief, their learning experiences and their belief in using mobile devices in teaching students computing. This study shows that the lecturer's academic support or pedagogical issue is in line with their schemas and beliefs.

Even though Bob is a computer scientist by training, he believes in the traditional teaching methods, and even though he is open to new ideas, he did not belief in changing his tested and trusted teacher-based teaching style, he believed that the approach is the best method to teach computing since he could understand computing through the same approach. This means that his role model for teaching were his past teachers. Unlike Sam who did not base his teaching belief on his teachers but on the interest of growth in BCS.

Despite the dichotomy in views and beliefs of the subjects, there exists some congruence, which is their belief in the use of email in communicating with students. Another congruence is the use of PowerPoints during teaching, and they all viewed PowerPoint slides as relatively inefficient as it depicts the shallow learning as teaching computing is deeper than just PowerPoint presentations (see figure 3).

Finally, the study findings does not suggest that Sam and Sarah's approach to technology or teaching is the appropriate or ideal approach for the department; it does not also suggest that Bob's method is not an ideal fit for a technology enhanced classroom. Whilst much remains to be explored within this phenomenon, they only among other understandings, give a comprehension of the pedagogy or hidden pedagogy of the college's computing curriculum. The findings suggests that the computing department could benefit from examining the efficiency of their teaching practices, instead of just assuming that the old traditional methods would fit with a technology enhanced teaching, could shift naturally towards embracing technology and implementing a technology supported strategies which will shift the teaching and learning methods to a seemingly compatible method which is a studentcentred approach. The college could also review the large class sizes and evaluate the general impact and its limitations, and they could also review the classrooms design and upgrade it to technology enhanced classes to improve the efficiency and effectiveness of teaching and learning computing.

\section{References}

Afreen, R. (2014). B ring your own device (BYOD) in higher education: opportunities and challenges. International Journal of Emerging Trends \& Technology in Computer Science, 3(1), 233-236.

Aikenhead, G. S., \& Jegede, O. J. (1999). Cross-cultural science education: A cognitive explanation of a cultural phenomenon. Journal of research in science teaching, 36(3), 269-287.

Berson, I., Berson, M., \& McGlinn Manfra, M. (2012). Touch, type, and transform: iPads in the social studies classroom. Social Education, 76(2), 88-91.

Brown, T. H., \& Mbati, L. S. (2015). Mobile learning: Moving past the myths and embracing the opportunities. The International Review of Research in Open and Distributed Learning, 16(2).

Buabeng-Andoh, C. (2012). Factors influencing teachers' adoption and integration of information and communication technology into teaching: A review of the literature. International Journal of Education and Development using Information and Communication Technology, 8(1), 136.

Cresswell, J. (2009). Research design: Qualitative, quantitative, and mixed methods approaches. Thosands Oaks, CA: Sage.

Crompton, H (2013). The Benefits and Challenges of Mobile Learning. Learning \& Leading with Technology, September/October 2013: 38-39.

Desai, M.S., Hart, J. and Richards, T.C., (2008). E-learning: Paradigm shift in education. Education, 129(2), p.327.

Dufresne, R. J., Gerace, W. J., Leonard, W. J., Mestre, J. P., \& Wenk, L. (1996). Classtalk: A classroom communication system for active learning. Journal of computing in higher education, 7(2), 3-47.

Engeström, Y. (1987). Learning by expanding: an activity-theoretical approach to developmental research. 
Helsinki: Orienta-Konsultit.

Engeström, Y. (1999). Activity theory and individual and social transformation. In Y. Engeström, R. Miettinen \& R. Punamäki (Eds.), Perspectives on activity theory (pp. 19-38). New York: Cambridge University Press.

Engeström, Y., \& Miettinen, R. (1999). Introduction. In Y. Engeström, R. Miettinen, \& R. Punamäki (Eds.), Perspectives on activity theory (pp. 1-16). New York: Cambridge University Press.

Ferguson, R. (2012). Learning analytics: drivers, developments and challenges. International Journal of Technology Enhanced Learning, 4(5-6), 304-317.

Fulantelli, G., Taibi, D., \& Arrigo, M. (2015). A framework to support educational decision making in mobile learning. Computers in Human Behavior, 47, 50-59.

Gorodetsky, M., \& Barak, J. (2016). Becoming learners/teachers in nomadic space. Teachers and Teaching, 22(1), 84-100.

Herrington, J., \& Oliver, R. (2000). An instructional design framework for authentic learning environments. Educational technology research and development, 48(3), 23-48.

Jacob, S. M., \& Issac, B. (2014a). The mobile devices and its mobile learning usage analysis. arXiv preprint arXiv:1410.4375.

Jacob, S. M., \& Issac, B. (2014b). Mobile learning culture and effects in higher education. arXiv preprint arXiv: 1410.4379.

Kaptelinin, V., \& Nardi, B. (2012). Activity theory in HCI: Fundamentals and reflections. Synthesis Lectures Human-Centered Informatics, 5(1), 1-105.

Kaptelinin, V., \& Nardi, B. A. (2006). Acting with technology: Activity theory and interaction design. MIT press.

Kirkwood, A., \& Price, L. (2014). Technology-enhanced learning and teaching in higher education: what is 'enhanced'and how do we know? A critical literature review. Learning, media and technology, 39(1), 6-36.

Kuznekoff, J. H., Munz, S., \& Titsworth, S. (2015). Mobile phones in the classroom: Examining the effects of texting, Twitter, and message content on student learning. Communication Education, 64(3), 344-365.

Lave, J., \& Wenger, E. (1991). Situated learning: Legitimate peripheral participation. Cambridge university press.

Lucas, N. (2013). One step forward, two steps back? The professionalisation of further education teachers in England. Research in Post-Compulsory Education, 18(4), 389-401.

Mehdipour, Y., \& Zerehkafi, H. (2013). Mobile learning for education: Benefits and challenges. International Journal of Computational Engineering Research, 3(6), 93-101.

Pachman, M, Logunov, A and Quinton, S (2011). TELT evaluation framework - refinement of TELT survey instrument (2nd iteration). Sydney, NSW: University of New South Wales.

Patton, M. (2002). Qualitative research and evaluation methods. Thousand Oaks, CA: Sage.

Picek, R., \& Grcic, M. (2013, June). Evaluation of the Potential Use of m-learning in Higher Education. In Information Technology Interfaces (ITI), Proceedings of the ITI 2013 35th International Conference on (pp. 63-68). IEEE.

Reeves, T. C. (2006). Design research from the technology perspective. In J. V. Akker, K. Gravemeijer, S. McKenney, \& N. Nieveen (Eds.), Educational design research (pp. 86-109). London: Routledge.

Reeves, T. C., \& Oh, E. J. (2007). Generation differences and educational technology research. In J. M. Spector, M. D. Merrill, J. J. G. van Merriënboer, \& M. Driscoll. (Eds.) Handbook of research on educational communications and technology (pp. 295-303). Mahwah, NJ: Lawrence Erlbaum Associates.

Rossing, J. P., Miller, W. M., Cecil, A. K., \& Stamper, S. E. (2012). iLearning: The future of higher education? Student perceptions on learning with mobile tablets. Journal of the Scholarship of Teaching and Learning, 12(2), 1-26.

Seppälä, P., \& Alamäki, H. (2003). Mobile learning in teacher training. Journal of computer assisted learning, $19(3), 330-335$

Sharples, M (2013). Mobile learning: research, practice and challenges. Distance Education in China 3(5): 5-11.

Spangler, S. C., Rodi, A., \& Kiernan, M. (2016). Case study: BYOD in the higher education classroom: Distraction or Disruption? The adoption of Spangler's 2016 digital human IT integration charting system. Issues in Information Systems, 17(3).

Thüs, H., Chatti, M. A., Yalcin, E., Pallasch, C., Kyryliuk, B., Mageramov, T., \& Schroeder, U. (2012). Mobile learning in context. International Journal of Technology Enhanced Learning, 4(5-6), 332-344.

Traxler, J (2007). Defining, discussing and evaluating mobile education: The moving finger writes and having writ .... International Review of Research in Open and Distance Learning 8(2) Retrieved from http://www.irrodl.org/index.php/irrodl/article/view/346.

Vavoula, G and Sharples, M (2009). Meeting the challenges in evaluating mobile learning: A 3-level evaluation framework. International Journal of Mobile and Blended Learning 1(2): 54-75, DOI: http://dx.doi.org/10.4018/jmbl.2009040104

Wilkinson, K., \& Barter, P. (2016). Do mobile learning devices enhance learning in higher education anatomy classrooms? Journal of Pedagogic Development, 6(1). 
Wishart, J. (2016). Debating the Future for Mobile Learning in Schools. Mobile Learning Futures-Sustaining Quality Research and Practice in Mobile Learning, 342.

Wu, W. H., Wu, Y. C. J., Chen, C. Y., Kao, H. Y., Lin, C. H., \& Huang, S. H. (2012). Review of trends from mobile learning studies: A meta-analysis. Computers \& Education, 59(2), 817-827.

Anietie Ukpabio, BSc (Hons), MSc, MBA, Cert Ed, MABE, MBCS, QTLS, FHEA I am a PhD Researcher at Lancaster University and a certified Business Analyst at IBM Client Innovation Centre.

My major interest posits in conducting research into the connections between our material surroundings, the technologies (beyond computers) that permeate them, and the ways we act, think and learn. Two recurring interests are how institutions design and evaluate their built environment domain to support opportunities for learning. More general interests include Activity Theory, networked and collaborative learning. Additionally, I also am concerned with collaborative work and group discussion in digitally-mediated environments, with a theoretical and practical commitment to social justice and equity within learning communities. I am interested in understanding the ways that sociocultural and sociotechnical elements inherent in applications of digital education operate to marginalise students who fall outside the ideations of dominant ideology.

My major qualifications are a first class honours degree in Computing from the University of Greenwich, an MSc. distinction in Information Technology from the Cardiff Metropolitan University, an MBA from University of Northampton. Apart from my previous software and IT industry experience, I am also a qualified teacher and my previous teaching background involves being a former Computing Lecturer at East Kent College, New Vic College and City College Norwich.

Acknowledgement: This research was undertaken as part of the PhD in E-research and Technology Enhanced Learning in the Department of Educational Research at Lancaster University. I am pleased to acknowledge the contribution of lecturers and peers in supporting the development of this study and its report as an assignment paper. 